\title{
SELECTIVE N-BENZOYLATION OF DESOXYCYTIDINE AND CYTIDINE
}

L. N. Nikolenko, V. N. Nezavibat'ko, and N. S. Tolmacheva

Khimiya Prirodnykh Soedinenii, Vol. 3, No. 5, p. 359, 1967

We have shown that a simple and direct method for the benzoylation of amino groups in nucleosides is their reaction with benzoylazide at $20^{\circ}-30^{\circ} \mathrm{C}$ in absolute pyridine.

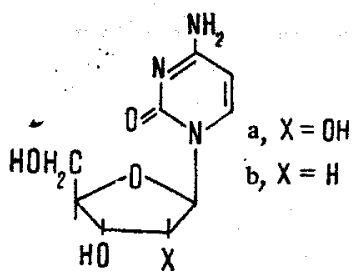

When cytidine (a) and deoxycytidine (b) were thermostated for $40 \mathrm{hr}$ with a tenfold excess of benzoylazide, the $\mathrm{N}$-benzoyl derivatives were formed quantitatively, and were isolated by evaporation in vacuum at room temperature and subsequent crystallization from water. The benzoyl derivatives were identified chromatographically in a thin layer of silica gel in the butanol-acetic acid-water $(4: 1: 1)$ system, and spectroscopically. The $R_{f}$ values corresponded to those of the benzoyl derivatives of cytidine and deoxycytidine obtained by other methods. The UV spectra corresponded to those given in the literature: $\lambda_{\max } 260$ and $303 \mathrm{~m} \mu, \lambda_{\min } 330$ and $284 \mathrm{~m} \mu$ [1].

REFERENCE

1. H. Schaller, G. Weimann, B. Lerch, and H. G. Khorana, J. Am. Soc., 85, 3821, 1963. 